\title{
Bio Efficacy of Nanoparticles of Sweet Flag Rhizome Powder
} on Callosobruchus analis

\author{
G. Harish*, A. Naganagoud, A. G. Sreenivas, Somashekar, \\ Sharangouda Hiregoudar and B. Kisan
}

ICAR-Directorate of Groundnut Research, Junagadh-362001, Gujarat, India

University of Agricultural Sciences, Raichur-584 104, Karnataka, India

*Corresponding author

\section{A B S T R A C T}

Keywords

Acoruscalamus, Callosobruchus analis,

Nanoparticles, Storage

Article Info

\section{Accepted:}

12 June 2021

Available Online:

19July 2021
Hyderbad Karnataka region is the pulse hub of Karnataka state. More than 100 of insect species cause damage to stored grains. Callosobruchus analis is one of the main pest of stored pegion pea in this region Use of sweet flag, Acoruscalamus (L.) is widely spread in Asia, North America and Europe. Nanotechnology is now creating a growing sense of excitement in the life science. Nanoparticles exhibit complete new or improved properties based on specific characteristics such as size, distributions and morphology. Green synthesis of nanoparticles is an emerging branch of nanotechnology $\mathrm{LC}_{50}$ value was found lowest (0.56) in 96 hours after treatment in sweet flag rhizome powder nanoparticles.

\section{Introduction}

Food grains produced are often stored for future needs, but due to improper handling and unscientific storage methods it has led to economic loss. Nearly 70 per cent of the grains annually produced in the country is retained by the farmers for their own food, cattle feed, seed etc. In storage the losses are mainly due to insects, mites and pathogens. Food grain losses due to insects alone accounts for nearly `1275 crores. In industrialized countries like Canada and Australia there is zero tolerance for insects in food grains (Pheloung and Macbeth, 2002). Up to 10 per cent storage losses have been reported due to storage pests from tropical countries. The most common method of store pest control followed at present is the application of malathion, fumigation with Aluminium phosphide, EDB, EDCT or other volatile substances. Though, these chemicals offer efficient protection against pests, cause certain undesirable side effects like residual toxicity, application hazards, environmental pollution, etc. Consumers are afraid to use food grains of this kind with toxic effects and residual chemicals (Nandi et al., 2008). 
Use of sweet flag, Acorus calamus (L.) is widely spread in Asia, North America and Europe. The essential oil obtained from rhizome (by steam distillation of Acorus calamus) showed pronounced insecticidal properties. Tablet form of sweet flag rhizome powder with cow dung ash as a carrier at 15 and 20 per cent concentration reduce the egg laying and seed damage even after 120 days of storage. Acorus calamus rhizomes at one per cent is effective against Rhizopertha dominica even after 180 days storage (Nandi et al., 2008).

Nanotechnology is now creating a growing sense of excitement in the life science. Nanoparticles exhibit complete new or improved properties based on specific characteristics such as size, distributions and morphology. Use of micro-organisms, plant extract or plant biomass could be an alternative to chemical and physical methods for the production of nanoparticles in an ecofriendly manner. Green synthesis of nanoparticles is an emerging branch of nanotechnology (Dhanasekaran et al., 2014).

\section{Materials and Methods}

Stored grain insect pests were collected from the infested lot of pigeon peaseeds from the central store of Main Agricultural Research Station, Raichur and the cultures of insects were further maintained in pre sanitized plastic container of two litre capacity separately pigeonpea seeds. The containers were covered with muslin cloth and fastened tightly with the help of rubber band. Fresh seeds were provided regularly and exposed separately for the multiplication of insects at room condition. The insects emerged from this culture were reared throughout the period of experimentation and used for infestation during the experiments. Sweet flag rhizome, Acorus calamus powder was brought from local market and was down sized to nano particle by following below mentioned protocol

\section{Synthesis of nanoparticles from sweet flag rhizome powder}

Sweet flag rhizome powder was brought from local market and was down sized to nanoparticle. Initially the sweet flag rhizome powder was subjected to ball milling (Cryo ball mill, Restch- Aller, 1-5, 42781, Germany) for 2 hours then the powder was dissolved in distilled water to prepare different concentrations (w/v). Dissolved sweet flag rhizome powder was stirred with magnetic stirrer for 30 minutes for dissolving and change in charge of particle to avoid aggregation and to achieve size reduction. The sweet flag rhizome solution was then subject to ultra sonication (Labman Scientific Instruments, LMUC-2.8L, India) for further size reduction under default setting for 30 minutes. Sonicated sweet flag rhizome particles were subjected to centrifugation in ultra high centrifuge (MPW Med. Instruments, MPW-350R, Poland) at $30000 \mathrm{rpm}$ for 10 minutes. After ultra high centrifugation sweet flag rhizome particles were again stirred with magnetic stirrer for 30 minutes for changing the charge of particle to avoid aggregation and were centrifuged at $60000 \mathrm{rpm}$ for 20 minutes. After each step size of the particles were analyzed by using Zeta size analyzer (ZETA Sizer, nano383 issue 5.0, Malvern, England) by Dispersion light scattering (DLS) method. This procedure were carried out based on different trial experiments.

The particles were then freeze dried with turbo vap (Turbo vap L V, Biostage, USA) and particle size was analyzed using scanning electron microscope (EVO 10, Carl Zeiss Microscopy, Germany). The particles were uniformly spread on the carbon tape and pasted to stubs for sputtering. Thin layer gold platinum was encapsulated to make the 
samples conductive using sputter coater. After sputtering the stubs were placed in chamber containing tungsten probe from where electrons were passed through the probe and back scattered electrons were captured to from a scanning electron microscope image. Based on the time required for back scattering of electrons the surface characters were given in the form of an image.

\section{Characterization of sweet flag rhizome nanoparticles}

Multiple parameter sensory probe (PCS testr 35) was used for studying the properties like ${ }_{\mathrm{P}} \mathrm{H}$, conductivity, total dissoluble solids (TDS) and salt content in both nano and macro particles of sweet flag rhizome powder.

The solubility of nano and macro particles of sweet flag rhizome powder was determined according to the method described by Chauca et al., (2004). One gram of powder was added to $100 \mathrm{ml}$ of distilled water and mixed thoroughly. An aliquot of $25 \mathrm{ml}$ of the supernatant were placed in a dried previously weighed moisture cups and immediately ovendried at $105^{\circ} \mathrm{C}$, for $5 \mathrm{~h}$. Solubility (per cent) was calculated by weight difference. The per cent solubility was calculated from the relation given below

Per cent solubility

$=\frac{w_{2}-w_{3}}{w_{2}-w_{1}} \times 100$

where, $\mathrm{W}_{1}=$ Empty weight of sample cups

$\mathrm{W}_{2}=$ Weight of sample cups with sample

$\mathrm{W}_{3}=$ Final weight of sample cups after drying

Bioassay was conducted as per standard protocol of insecticide resistance action committee (IRAC). Callosobruchus analis Fab. adults were collected from stock culture and were separated from the culture prior to testing. Ten adults were placed in each vial. Adult bruchids were held without food for one hour at room temperature before treatment. Filter papers were pre-treated with nano form of sweet flag rhizome at 0.50, 1.00, 1.50, 2.00 and 2.50 per cent concentrations by spraying one $\mathrm{ml}$ solution by using potters tower and were placed in petriplates. Ten freshly emerged adults were released into the petriplates containing test papers. Each treatment was replicated thrice along with set of control treatment with water spray and normal sweet flag rhizome of 2.50 per cent concentrations. The per cent mortality of the insects in all the treatments including water spray were observed after 24, 48, 72 and 96 hours after treatment (HAT).Probit analysis was done using finney method (Finney, 1971) and $\mathrm{LC}_{50}$ was calculated.

\section{Results and Discussion}

Forty adults of $C$. analis were subjected to bioassay and $\mathrm{LC}_{50}$ value was found lowest (0.56) in 96 hours after treatment in sweet flag rhizome powder nanoparticles with a fiducial limit of 0.35 to 0.90 (table 2). In case of sweet flag rhizome powder macro particles the $\mathrm{LC}_{50}$ value was 0.64 with a fiducial limit of 0.40 to 1.01 after 96 hours after treatment. The $\mathrm{R}^{2}$ and $\chi^{2}$ values were 0.74 and 5.85 , respectively in nanoparticles of sweet flag rhizome powder, whereas $\mathrm{R}^{2}$ and $\chi^{2}$ values were 0.84 and 2.79 , respectively in macro particles of sweet flag rhizome powder.

Laboratory studies were conducted to study the bioefficacy of sweet flag rhizome powder at different concentrations (by weight) against the pulse beetle. Reviews pertaining to use of nanoparticles are not available hence results are discussed with nearest relevant reviews.

The highest mortality was recorded in 2.50 per cent concentration with 20,30, 57.50 and 
92.50 per cent in nanoparticles of sweet flag rhizome powder after 24, 48, 72 and 96 hours of treatment. Similarly highest mortality was recorded in 2.50 per cent concentration with $12.5,25,42.50$ and 85 per cent after $24,48,72$ and 96 hours of treatment in macro particles of sweet flag rhizome powder. This work has been done for the first time hence no reviews are available to compare the above results. ElNohal et al., (1989) studied the toxic effect of the extracts of $A$. calamus on adults of $C$. chinensis. Nandi (2007) recorded 13.33, 77.66 and 97.66 per cent adult mortality after 24, 48 and 72 hours after treatment.

Dhanasekaran et al., (2014) reported that silver nanoparticles were synthesised using $A$. calamus (sweet flag) and aqueous $\mathrm{AgNo}_{3}$ solution changed from golden yellow to dark brown colour after incubation

Forty adults of $C$. analis were subjected to bioassay and results were $\mathrm{LC}_{50}$ value was found lowest (0.56) in 96 hours after treatment in sweet flag rhizome powder nanoparticles. In case of sweet flag rhizome powder macro particles the $\mathrm{LC}_{50}$ value was 0.64 .
This work has been done for the first time hence no reviews are available to compare the above results. Latha et al., (2015) reported $\mathrm{LC}_{50}$ of $3400 \mathrm{ppm}$ after 72 hours of treatment. $\mathrm{LC}_{50}$ values of ethanolic extract of $A$. calamus rhizome against Drosophila melanogaster larvae and adults (male and female) were 109.54, 52.51 and $41.11 \mathrm{mg} / \mathrm{L}$ respectively as reported by Kumar et al., (2015).

The particles of sweet flag rhizome was down sized at each step and was successfully converted nanoparticle of size $76.35 \mathrm{~nm}$ as measured by dynamic light scattering (DLS) method in Zeta size analyzer. Scanning electron microscope images also confirmed the particles $(92.12 \mathrm{~nm})$ were converted to nanoform. Total dissoluble solids (TDS) and salt contents were $1.13 \mathrm{ppt}$ and 808 respectively which increased to $1.17 \mathrm{ppt}$ and 830 respectively when converted to nanoform. Similarly conductivity also increased from $1596 \mu / \mathrm{s}$ to $1646 \mu / \mathrm{s}$ when converted to nanoparticles

Table.1 Synthesis and characterization of nanoparticles from sweet flag rhizome powder

\begin{tabular}{|c|c|c|c|}
\hline \multicolumn{3}{|c|}{ Method } & Particle size \\
\hline \multicolumn{3}{|c|}{ Ball milling } & $385 \mathrm{~nm}$ \\
\hline \multicolumn{3}{|c|}{ Ball milling $\rightarrow$ magnetic sterring } & $380 \mathrm{~nm}$ \\
\hline \multicolumn{3}{|c|}{ Ball milling $\rightarrow$ Sonication } & $320 \mathrm{~nm}$ \\
\hline \multicolumn{3}{|c|}{ Ball milling $\rightarrow$ Centrifuge(30000 rpm for $10 \mathrm{~min})$} & $260 \mathrm{~nm}$ \\
\hline \multicolumn{3}{|c|}{ Ball milling $\rightarrow$ magnetic sterring $\rightarrow$ Centrifuge $(60000 \mathrm{rpm}$ for $20 \mathrm{~min})$} & $76.35 \mathrm{~nm}$ \\
\hline \multicolumn{4}{|c|}{ characterization of from sweet flag rhizome particles } \\
\hline Characters & Normal sized particle & \multicolumn{2}{|c|}{ Nano sized particle } \\
\hline $\mathbf{P}_{\mathbf{H}}$ & 6.00 & \multicolumn{2}{|c|}{5.00} \\
\hline TDS & $1.13 \mathrm{ppt}$ & \multicolumn{2}{|c|}{$1.17 \mathrm{ppt}$} \\
\hline Salt & $808 \mathrm{ppm}$ & \multicolumn{2}{|c|}{$830 \mathrm{ppm}$} \\
\hline Conductivity & $1596 \mu / \mathrm{s}$ & \multicolumn{2}{|c|}{$1646 \mu / \mathrm{s}$} \\
\hline Solubility & 99.5 & \multicolumn{2}{|c|}{99.8} \\
\hline Count rate (KCPS*) & 379.3 & \multicolumn{2}{|c|}{321.6} \\
\hline
\end{tabular}

* kinetic counts per second 
Table.2 Mortality (in percentage) of Callosobruchus analis exposed to different doses of sweet flag rhizome powder

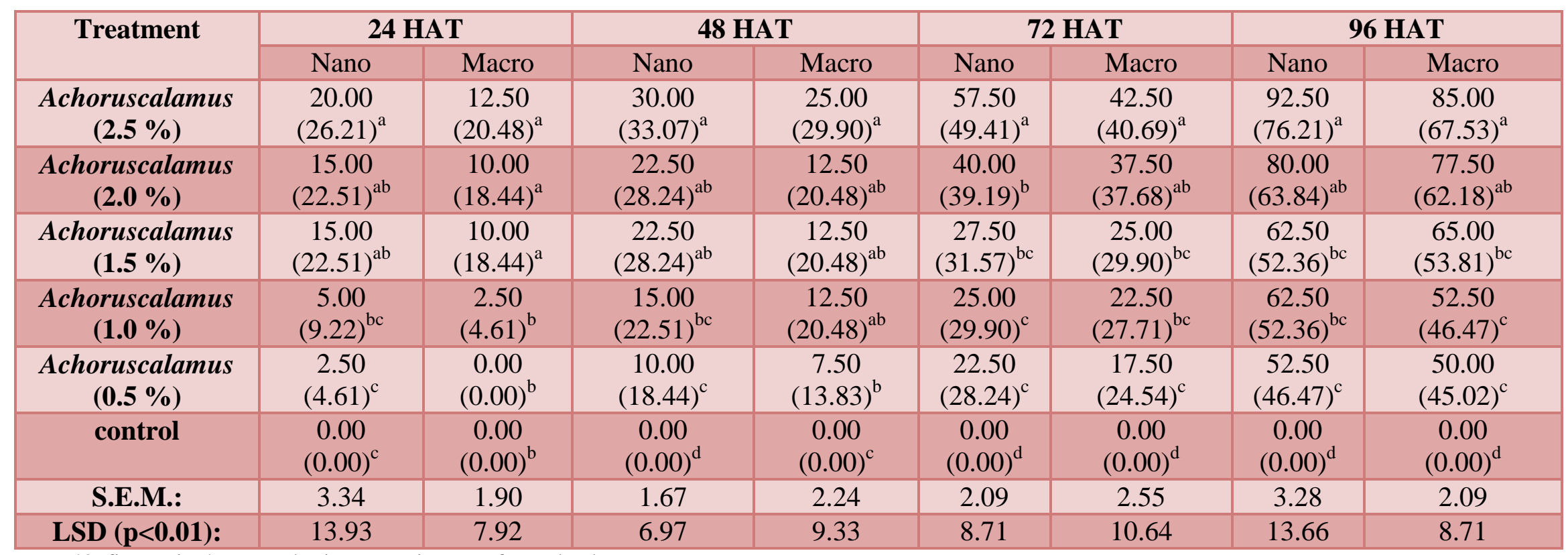

$\mathrm{N}=40$; figures in the parenthesis are arcsine transformed values 
The highest mortality was recorded in 2.50 per cent concentration with 20, 30, 57.50 and 92.50 per cent mortality in nanoparticles of sweet flag rhizome powder after 24, 48, 72 and 96 hours of treatment. $\mathrm{LC}_{50}$ value was found lowest (0.56) in 96 hours after treatment in sweet flag rhizome powder nanoparticles.

\section{References}

Chauca, M. C., Stringheta, P. C., Ramos, A. M. and Vidal, J. C., 2004, Effect of the carriers on the microstructure of mango powder obtained by spray drying and its functional characterization. Innovative Food Sci. and Emerging Technol., 6: 420-428.

Dhanasekaran, S., Karunakaran, S., Amutha, R., Suruthipriyadharshini, S. and Jayalakshmi, K., 2014, Biosynthesis of silver nanoparticles using Acorus calamus and its antibacteral activity.Int. J. Nanomaterials and Biostructures, 4(1): 16-20.

El-Nohal, A. K. M., Schmidt, G. H. and Risha, E. M., 1989, Vapours of Acorus calamus oil - A space treatment for stored product insects.J. Stored Prod.
Res., 25: 211-216.

Finney, D. J., 1971, Probit analysis, $3^{\text {rd }}$ ed. Cambridge University press, London. 333p.

Kumar, A., Sharma, S. and Verma, G., 2015, Insecticidal and genotoxic potential of Acorus calamus rhizome extract against Drosophila melanogaster.Asian J. Pharm. Clin. Res., 8(4): 113-116.

Latha, H. C., Naganagoud, A., Sowmya, H. C. and Khan, H., 2015, Bioassay of sweet flag rhizome (Acorus calamus L.) on pulse beetle (Callosobruchus analis L.) population. J. Expt.Zool., 18(1): 289-291.

Nandi, R., Naganagoud, A. and Patil, B.V., 2008, Effect of sweet flag rhizome, Acorus calamus L. formulations with cow dung ash as a carrier against Callasobruchus chinensis Linn. In Pigeonpea. Karnataka J. Agric. Sci., 21(1): 45-48.

Pheloung, P. and Macbeth, F., 2002, Export inspection: adding value to Australia's grain. In: Stored grain research laboratory, ed. Canberra, Australia. pp. 15-17.

\section{How to cite this article:}

Harish, G., A. Naganagoud, A. G. Sreenivas, Somashekar, Sharangouda Hiregoudar and Kisan, B. 2021. Bio Efficacy of Nanoparticles of Sweet Flag Rhizome Powder on Callosobruchus analis. Int.J.Curr.Microbiol.App.Sci. 10(07): 164-169.

doi: https://doi.org/10.20546/ijcmas.2021.1007.019 